Article

\title{
A Flywheel Energy Storage System Based on a Doubly Fed Induction Machine and Battery for Microgrid Control
}

\author{
Thai-Thanh Nguyen, Hyeong-Jun Yoo and Hak-Man Kim * \\ Department of Electrical Engineering, Incheon National University, 12-1 Songdo-dong, Yeonsu-gu, \\ Incheon 406-840, Korea; E-Mails: ntthanh@inu.ac.kr (T.-T.N.); yoohj@inu.ac.kr (H.-J.Y.) \\ * Author to whom correspondence should be addressed; E-Mail: hmkim@inu.ac.kr; \\ Tel.: +82-32-835-8769; Fax: +82-32-835-0773.
}

Academic Editor: William Holderbaum

Received: 2 February 2015 / Accepted: 26 May 2015 / Published: 1 June 2015

\begin{abstract}
Microgrids are eco-friendly power systems because they use renewable sources such as solar and wind power as the main power source. However, the stochastic nature of wind and solar power is a considerable challenge for the efficient operation of microgrids. Microgrid operations have to satisfy quality requirements in terms of the frequency and voltage. To overcome these problems, energy storage systems for short- and long-term storage are used with microgrids. Recently, the use of short-term energy storage systems such as flywheels has attracted significant interest as a potential solution to this problem. Conventional flywheel energy storage systems exhibit only one control mode during operation: either smoothing wind power control or frequency control. In this paper, we propose a new flywheel energy storage system based on a doubly fed induction machine and a battery for use with microgrids. The new flywheel energy storage system can be used not only to mitigate wind power fluctuations, but also to control the frequency as well as the voltage of the microgrid during islanded operation. The performance of the proposed flywheel energy storage system is investigated through various simulations using MATLAB/Simulink software. In addition, a conventional flywheel energy storage system based on a doubly fed induction machine is simulated and its performance compared with that of the proposed one.
\end{abstract}

Keywords: microgrid; flywheel energy storage (FES); doubly fed induction machine; frequency control; smoothing wind power 


\section{Introduction}

A microgrid is a small-scale power system, which can operate in two modes: grid-connected mode and islanded mode. Generally, a microgrid is comprised of distributed energy resources (DERs), distributed energy storage systems, and loads [1,2]. DERs such as diesel generators, natural gas generators, and fuel cells are placed along with the loads. Besides, renewable energy sources such as solar and wind powers can alleviate the environmental problems caused by burning fossil fuels. However, the drawback of renewable energy sources is the power fluctuations due to the stochastic nature of wind and solar power. The fluctuations must be compensated to meet the power-quality requirements [3-5].

In order to reduce wind or solar power fluctuations, short-term energy storage systems such as superconducting magnetic energy storage (SMES) systems, electrical double-layer capacitors (EDLCs), flywheel energy storage (FES) systems, as well as long-term energy storage systems such as battery energy storage systems (BESS) are installed in the microgrid. A fast response is necessary to compensate for the fluctuations in wind power, therefore a BESS might not be a good alternative, as it charges and discharges slowly. A BESS is often used in the microgrid equipped with a solar photovoltaic generator [6,7]. FES systems, SMES systems and EDLCs can be used for smoothing the power generated by wind, given their fast response and efficiency [8-21]. However, the use of SMES systems and EDLCs is still limited, due to the high initial investment and maintenance costs involved [13]. This study will focus on FES systems and wind power to show how the fluctuations in wind power are handled by the proposed FES system.

Of late, using an FES system in microgrids is being explored as a potential solution for improving the power quality, as such a system is highly reliable, has short response times, long lives, and low overall costs. The use of an FES system to improve the degree of integration of wind power in alternating (AC) microgrids has already been investigated [14-16]. The FES system can control not only the frequency but also the voltage of the microgrid during islanded operation. In the grid-connected mode, the FES system is used to compensate for wind power fluctuations. In addition, the FES system can be coupled with the wind generator using a doubly fed induction generator [17-20], for smoothing the wind power. Further, in order to improve the performance of FES systems in direct current (DC) microgrids, Chang has suggested introducing an active disturbance rejection control [21].

The main components of an FES system are a rotating mass, a motor-generator machine, and converters. Three types of motor-generator machine can be used: a permanent-magnet machine, an induction machine used as a doubly fed induction machine (DFIM), or a switched reluctance machine [22-24]. FES systems based on a permanent-magnet machine or a switched reluctance machine require converters with significantly higher power ratings than FES systems based on a DFIM. As a result, the overall cost of FES systems based on a permanent-magnet machine or a switched reluctance machine is higher than that of those based on a DFIM. In 1996, the World's first low-speed FES system based on a DFIM was installed and commissioned in Japan at the Chujowan substation of the Okinawa Electric Power Company [25]. This FES system, which has an energy rating of $200 \mathrm{MJ}$ and power of $20 \mathrm{MW}$, is used to control the frequency of the utility grid. Thus, very large FES systems can be used in microgrids to successfully regulate the frequency. However, the cost of such FES systems is very high, owing to cost of their components such as the mass, shaft, motor/generator, bearings, cooling unit, and 
containment unit. A small FES system that stores a small fraction of the energy can be suitable for handling wind power fluctuations in grid-connected mode because a relatively small amount of energy is required. However, it might be inappropriate to handle frequency of microgrid in islanded mode due to the need for a larger amount of energy. To overcome this problem, in this paper, we propose a new FES system based on a DFIM and a battery for use in microgrids. This FES system can control its power to compensate for fluctuations in wind power in grid-connected mode, in addition to controlling the frequency and voltage of the microgrid in islanded mode. The efficacy of the proposed FES system is verified via simulations in the MATLAB/Simulink environment.

The rest of this paper is organized as follows: Section 2 introduces conventional FES system and the proposed FES system. In Section 3, the proposed FES control system, which has a two-level control scheme, is described. Section 4 describes the microgrid system used to test the performance of the proposed FES system. In Section 5, the simulation results for three different scenarios are described. Finally, the main conclusions of the study are summarized in Section 6.

\section{Proposed FES System}

A conventional FES system based on a DFIM and the proposed FES system are shown in Figure 1. The conventional FES system consists of a flywheel, an induction machine that acts as both a motor and a generator, and a back-to-back converter system. The difference between the proposed FES system and the conventional one is that the former has an additional battery with a boost-buck DC/DC converter connected to the DC-link back-to-back converter system. The back-to-back converter system is divided into two components: a machine-side converter (MSC) and a grid-side converter (GSC). The MSC is connected to the rotor winding while the GSC is connected to the grid through a filter and a transformer.

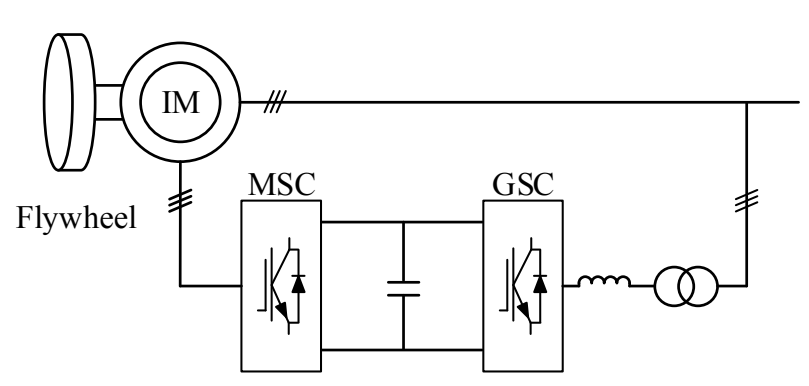

(a)

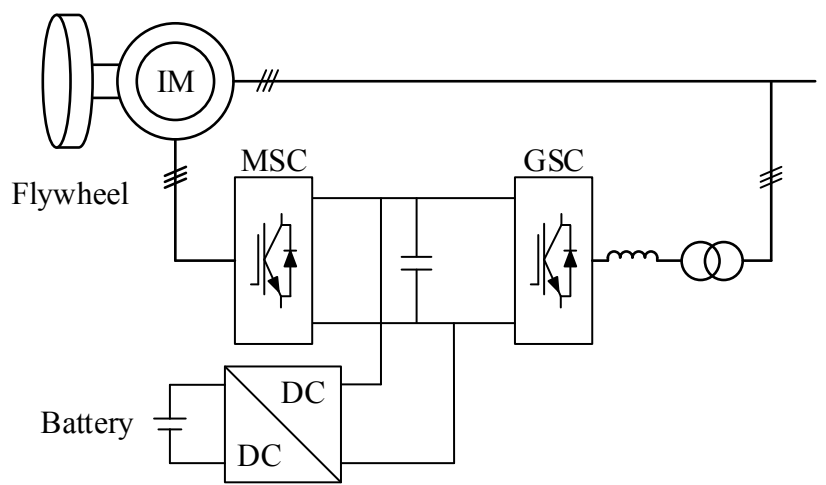

(b)

Figure 1. FES systems: (a) conventional FES system; (b) proposed FES system.

The operating principle of the FES system is that a rotating mass can be used to store and retrieve energy. The flywheel, which is connected to an induction machine, is a mass with a high inertia. Thus, in this study, an induction machine with a high inertia was used to model the FES system in MATLAB/Simulink. The energy stored by the FES system is in the form of kinetic energy, $E$, which can be represented by Equation (1) [26]: 


$$
E=\frac{1}{2} J \omega^{2}
$$

where $\omega$ is the rotational speed of the FES system and $J$ is its moment of inertia.

The available energy stored in the FES system, $\Delta E$, is represented by Equation (2):

$$
\Delta E=\frac{1}{2} J\left(\omega_{\max }^{2}-\omega_{\min }^{2}\right)
$$

where $\omega_{\max }$ and $\omega_{\min }$ are the maximum and minimum speeds of the FES system, respectively.

The power exchanged with the stator circuit and the electrical torque of the induction machine can be expressed as follows [27]:

$$
\begin{gathered}
S_{s}=j \frac{3}{2}\left(\omega+\omega_{r}\right) \widehat{\lambda_{s}} \frac{\widehat{\lambda_{s}}-L_{m} i_{q d r}^{*}}{L_{s}} \\
T_{e}=\frac{3}{2} \frac{L_{m}}{L_{s}} \widehat{\lambda}_{s} \operatorname{Im}\left\{i_{q d r}^{*}\right\}
\end{gathered}
$$

where $\omega_{r}$ is the electrical angular velocity $\left(\omega=\omega_{0}-\omega_{r}\right), \widehat{\lambda_{s}}$ is the stator flux linkage, $L_{m}$ is the magnetizing inductance, $L_{s}$ is the stator inductance, and $i_{q d r}^{*}$ is the conjugate of the rotor current.

In this study, the rotor reference frame was used to convert the abc-frame into a dq-frame using the Clarke and Park transformation. As a result, the rotor current represented in the dq-frame is given by the following expression [28]:

$$
i_{q d r}=i_{q r}+j i_{d r}
$$

Substituting $i_{q d r}$ from Equation (5) in Equations (3) and (4), we get:

$$
\begin{gathered}
S_{s}=-\frac{3}{2}\left(\omega+\omega_{r}\right) \widehat{\lambda_{s}} \frac{L_{m} i_{d r}}{L_{s}}+j \frac{3}{2}\left(\omega+\omega_{r}\right) \widehat{\lambda_{s}} \frac{\widehat{\lambda_{s}}-L_{m} i_{q r}}{L_{s}} \\
T_{e}=-\frac{3}{2} \frac{L_{m}}{L_{s}} \widehat{\lambda_{s}} i_{d r}
\end{gathered}
$$

The real and reactive powers of the stator are given by:

$$
\begin{gathered}
P_{s}=\operatorname{Re}\left\{S_{s}\right\}=-\frac{3}{2}\left(\omega+\omega_{r}\right) \hat{\lambda_{s}} \frac{L_{m} i_{d r}}{L_{s}} \\
Q_{s}=\operatorname{Im}\left\{S_{s}\right\}=\frac{3}{2}\left(\omega+\omega_{r}\right) \hat{\lambda_{s}} \frac{\widehat{\lambda_{s}}-L_{m} i_{q r}}{L_{s}}
\end{gathered}
$$

It can be seen from Equations (7)-(9) that the electrical torque and stator power of an induction machine can be controlled by the rotor current.

\section{Control System of the Proposed FES System}

The control system of the proposed FES system is shown in Figure 2; it comprises three control systems: the MSC control system, the GSC control system, and the battery-side control system. For each control system, a two-level control scheme based on the principle of flux orientation control is designed, that is, each control system uses a current controller and an external controller. In contrast, the conventional FES system has only two control systems: the MSC and GSC control systems. The current 
controllers of the MSC and GSC in both the conventional FES system and the proposed FES system are similar. However, the external control systems of the two FES systems are different, because the proposed FES system uses a battery.

Flywheel

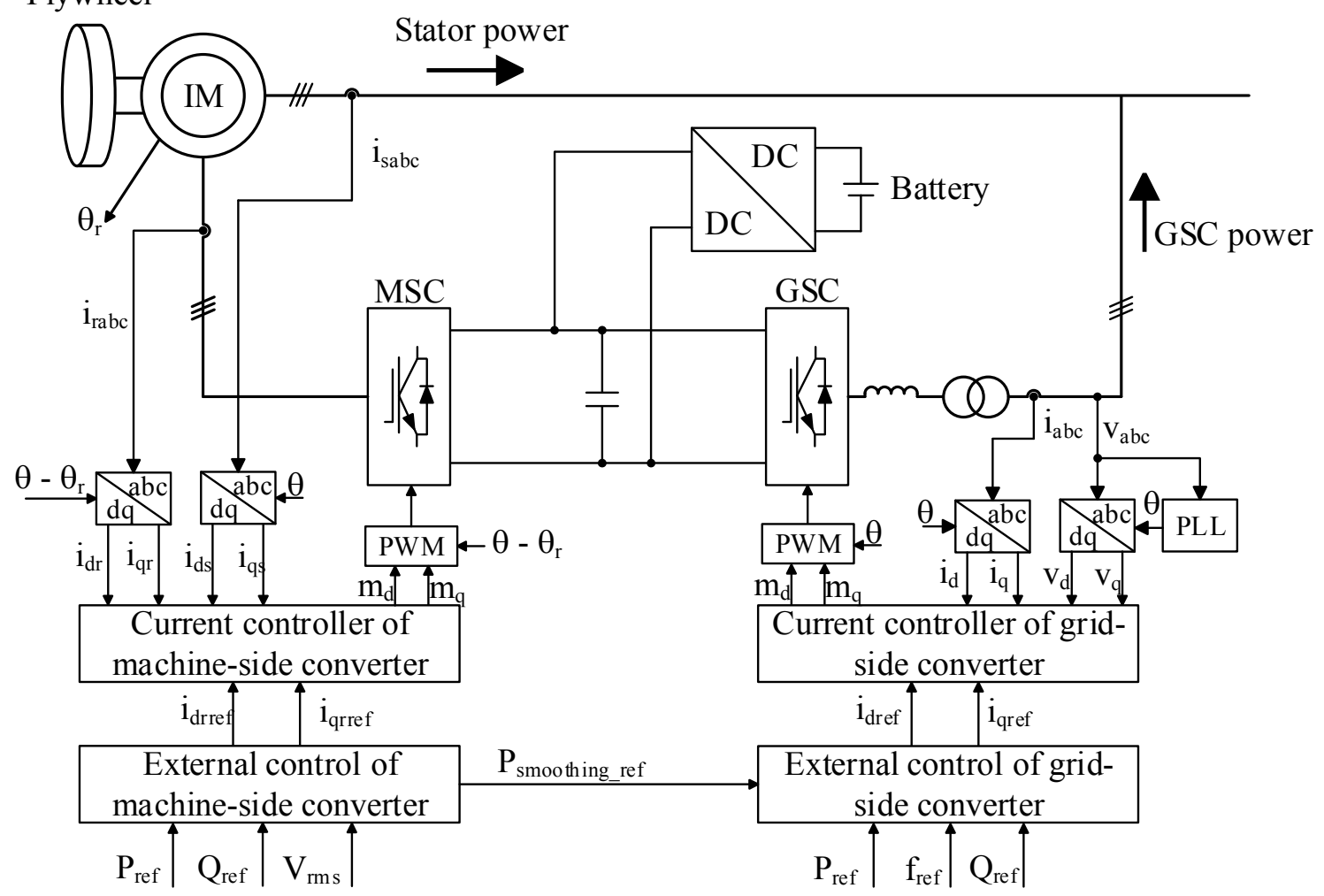

Figure 2. Control systems of the proposed FES system.

\subsection{Current Controller in the Machine-Side Converter Control System}

The MSC controls the stator power of the induction machine. The controller is based on the equations of the induction machine represented in the dq-frame. The equations representing the induction machine such that all the rotor variables refer to the stator windings are as follows [28]:

$$
\begin{gathered}
v_{q r}^{\prime}=R_{r}^{\prime} i_{q r}^{\prime}+\frac{d \lambda_{q r}^{\prime}}{d t}+\left(\omega_{0}-\omega_{r}\right) \lambda_{d r}^{\prime} \\
v_{d r}^{\prime}=R_{r}^{\prime} i_{d r}^{\prime}+\frac{d \lambda_{d r}^{\prime}}{d t}-\left(\omega_{0}-\omega_{r}\right) \lambda_{q r}^{\prime} \\
\lambda_{q r}^{\prime}=L_{r}^{\prime} i_{q r}^{\prime}+L_{m} i_{q s} \\
\lambda_{d r}^{\prime}=L_{r}^{\prime} i_{d r}^{\prime}+L_{m} i_{d s}
\end{gathered}
$$

with $i_{q d r}^{\prime}=\frac{N_{r}}{N_{s}} i_{q d r} ; v_{q d r}^{\prime}=\frac{N_{s}}{N_{r}} v_{q d r} ; L_{r}^{\prime}=\left(\frac{N_{s}}{N_{r}}\right)^{2} L_{r} ; R_{r}^{\prime}=\left(\frac{N_{s}}{N_{r}}\right)^{2} R_{r} ; \lambda_{q d r}^{\prime}=\frac{N_{s}}{N_{r}} \lambda_{q d r}$

where $L_{r}$ and $R_{r}$ are the rotor inductance and resistance, respectively; $v_{q d r}$ and $i_{q d r}$ are the $q$ - and $d$-axis rotor voltage and current, respectively; $\lambda_{q d r}$ is the $d$ - and $q$-axis flux linkage of the rotor; $i_{d q s}$ is the $q$ - and $d$-axis stator current; and $N_{s}$ and $N_{r}$ are the numbers of turns of the stator and rotor coils, respectively. 
Substituting $\lambda_{d r}^{\prime}$ and $\lambda_{q r}^{\prime}$ from Equations (12) and (13) in Equations (10) and (11), we have:

$$
\begin{aligned}
& v_{d r}^{\prime}=R_{r}^{\prime} i_{d r}^{\prime}+u_{d}-\left(\omega_{0}-\omega_{r}\right)\left(L_{r}^{\prime} i_{q r}^{\prime}+L_{m} i_{q s}\right) \\
& v_{q r}^{\prime}=R_{r}^{\prime} i_{q r}^{\prime}+u_{q}+\left(\omega_{0}-\omega_{r}\right)\left(L_{r}^{\prime} i_{d r}^{\prime}+L_{m} i_{d s}\right)
\end{aligned}
$$

The control block diagram for a current controller of the MSC system based on Equations (14) and (15) is shown in Figure 3. The currents $i_{d r}^{\prime}$ and $i_{q r}^{\prime}$ can be controlled by two new control inputs $u_{d}=\frac{d \lambda_{d r}^{\prime}}{d t}$ and $u_{q}=\frac{d \lambda_{q r}^{\prime}}{d t}$, respectively.

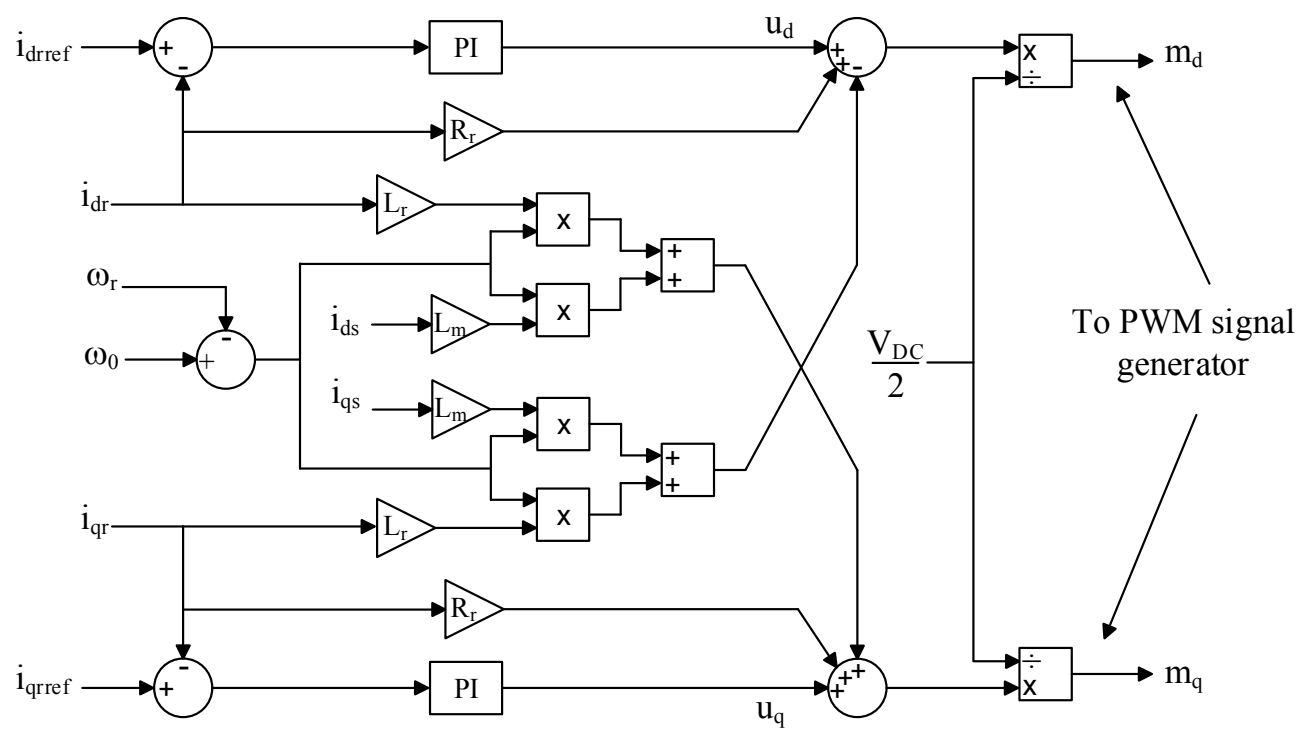

Figure 3. Control block diagram of the current controller of the machine-side converter.

\subsection{Current Controller in the Grid-Side Converter and Battery-Side Converter Control System}

Vector controller techniques are used to design the current controller of the GSC control system. The GSC of the FES system is similar to that of the wind energy system. Thus, the current control system described in [29] was used in the present study. The current controller in the GSC control system uses current control loops with the decoupling dynamics of the dq currents and grid voltage feed-forward, in order to improve their performance.

The battery-side converter uses a bi-directional DC-DC converter to maintain the DC-link voltage of the back-to-back converter. This converter, which is connected to the battery, has two operational modes, which depend on whether the battery is charging or discharging. If the DC-link voltage increases, the converter operates in the buck mode to charge the battery. In contrast, if the DC-link voltage decreases, the converter operates in the boost mode to discharge the battery [30]. For the sake of simplicity, in this study, we assumed an ideal battery without considering its state of charge.

\subsection{External Control System}

The external control systems of the proposed FES system are shown in Figure 4. The proposed FES system has three control systems, which play different roles. The MSC control system has the role of smoothing the wind power, the GSC controls the real power of the GSC (GSC power) and the frequency 
of the microgrid, and the battery-side converter controls the DC-link voltage of the back-to-back converter. In comparison, the conventional FES system has only two control systems. The MSC controls the FES power in order to compensate for the variations in the wind power and controls the frequency of the microgrid during islanded mode (the FES power includes the stator power and the GSC power of the FES system). The GSC controls the DC-link voltage of the back-to-back converter.

The MSC controls the stator power of the proposed FES system, in order to smoothen the fluctuations in the wind power in both the grid-connected mode and the islanded mode. The external control scheme of the MSC control system is shown in Figure 4a. The amount of wind power generated is measured, and the power is made to pass through a first-order low-pass filter for smoothing. The smoothened wind power is subtracted from the total wind power to generate the reference power $\left(P_{\text {smoothing_ref }}\right)$. In addition, it is important to control the $\mathrm{AC}$ grid voltage when the microgrid switches to operate in the islanded mode. Thus, an additional role of the MSC control system is to control the AC grid voltage by controlling the rotor current, $i_{q r}$.

The role of the GSC control system of the proposed FES system is to control the constant power in the grid-connected mode and to control frequency in the islanded mode, as shown in Figure $4 \mathrm{~b}$. In the islanded mode, the frequency control of the GSC control system needs to coordinate with the wind-power-smoothing control of the MSC control system. Consequently, the frequency droop control scheme is a suitable one for the GSC control system. However, a major drawback of the droop control is the existing steady-state error [31]. Thus, in this study, a new droop control scheme for which the steady-state error is removed is used in the frequency control scheme. The steady-state error is removed by a new feedback signal through the proportional-integral (PI) controller, as shown in Figure $4 \mathrm{~b}$.

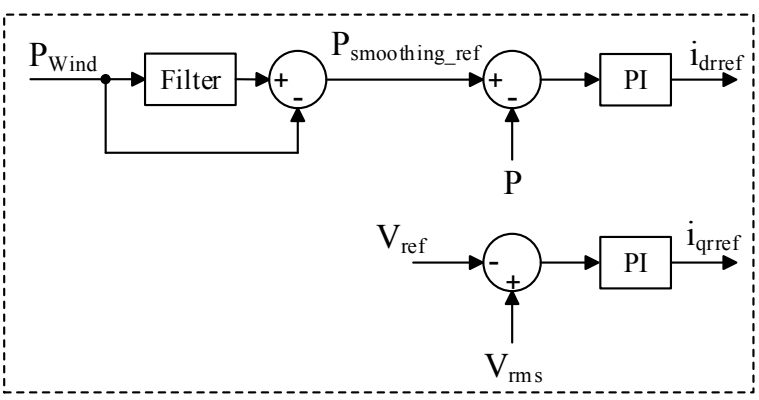

(a)

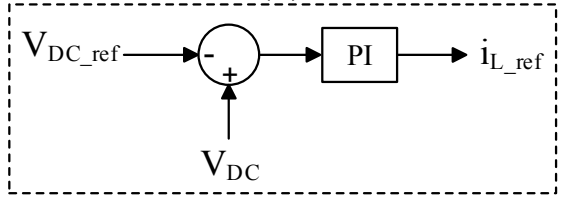

(c)

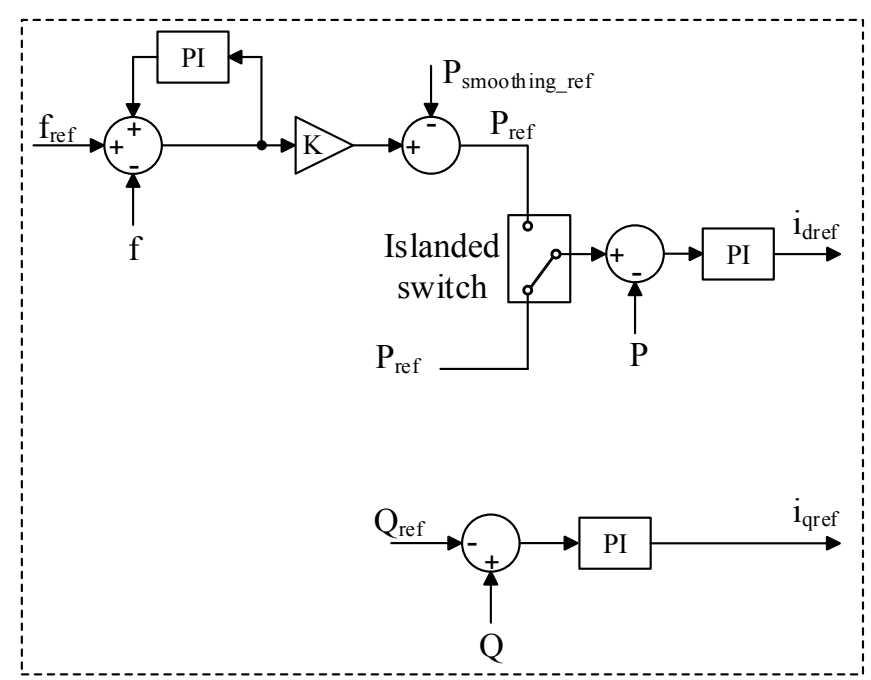

(b)

Figure 4. External control systems: (a) MSC control system; (b) GSC control system; (c) battery-side converter control system.

\section{Test Microgrid}

The test microgrid system (Figure 5) used in the study included several components: a diesel generator, a consumer load, a wind generator, and an FES system. In this study, for the sake of simplicity, we used a fixed-speed wind energy conversion system (WECS) [32]. 


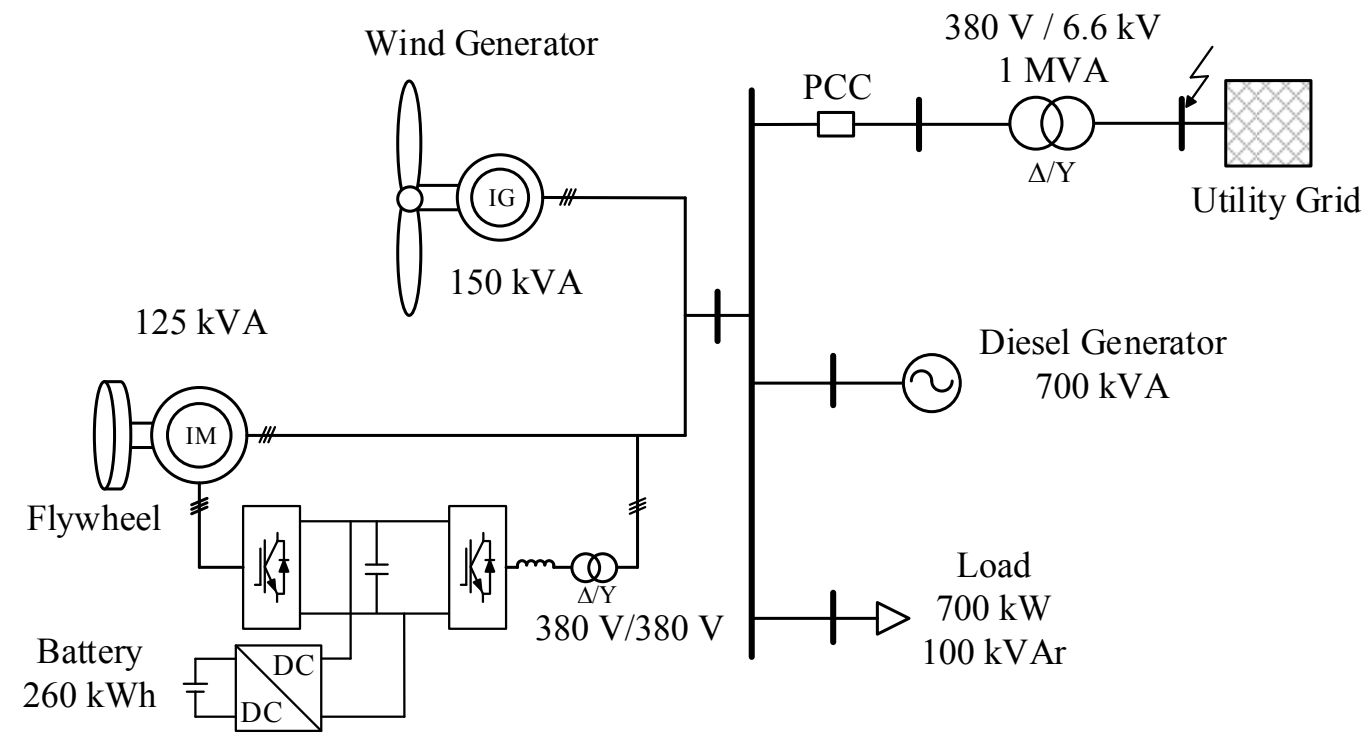

Figure 5. Configuration of the microgrid.

The output power of the wind generator varies with the wind speed. Figure 6 shows the actual wind speed data; the mean speed was $9 \mathrm{~m} / \mathrm{s}$. The output power of the wind generator corresponding to the mean wind speed was $50 \mathrm{~kW}$. An FES system with a speed range of 2520-4680 rpm was installed near the wind generator. According to Equation (2), the available energy stored in the FES system, which had a moment of inertia, $J$, of $37.6 \mathrm{kgm}^{2}$, was $3.2 \mathrm{MJ}$. In order to eliminate the harmonics generated from the GSC, a filter and a $\Delta-Y$ transformer are installed on the GSC. In the proposed FES system, a $600-\mathrm{V}$ battery is connected to the capacitor through the bi-directional converter, in order to regulate the DC-link voltage at $2200 \mathrm{~V}$. The main power supply is from the diesel generator, which has a rating of $700 \mathrm{kVA}$. Additional power is supplied from the wind generator and the FES system.

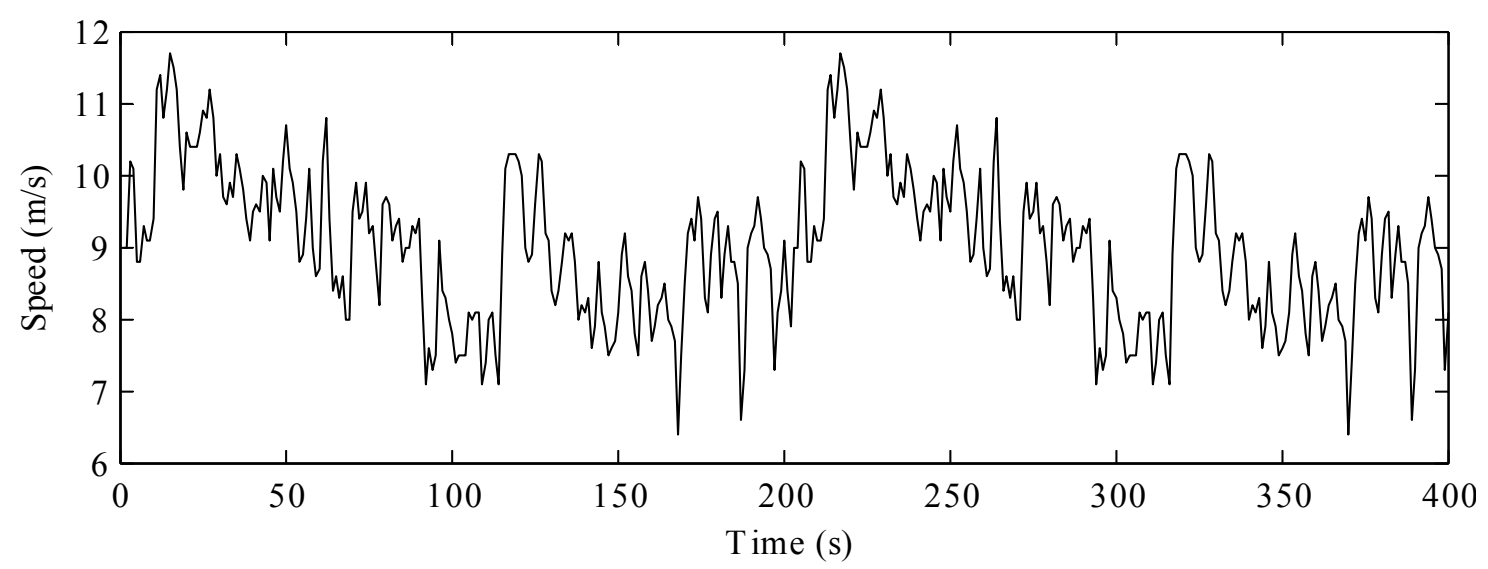

Figure 6. Actual wind speed data.

The microgrid is connected to the utility grid by a step-up transformer. The circuit breaker is placed at the point of common coupling (PCC) to connect or disconnect the microgrid with the utility grid. The circuit breaker is opened when the protection system detects a severe fault or strong oscillations in the power on the utility grid side. 


\section{Simulation Results}

Three scenarios were considered to validate the performance of the proposed FES system. In the first scenario, the microgrid operates in the grid-connected mode; this is carried out to test the performance of the FES system in the smoothing-of-wind-power mode. The second scenario simulates a case where a severe fault occurs on the utility grid side. Thus, the microgrid operates in the islanded mode. The FES system has to maintain the frequency as well as the voltage of the microgrid. Finally, the third scenario considers the rating of the FES system, which is reduced by decreasing its moment of inertia. The conventional FES system is also simulated for a comparison with the proposed FES system. The simulations are performed in the MATLAB/Simulink environment.

\subsection{Smoothing-of-Wind-Power Mode}

In the grid-connected mode, the MSC controls the real power of the FES system, in order to compensate for the fluctuations in the wind power. The wind power fluctuates with the wind speed. However, by effectively compensating for the variations in the wind power, the total real power of the wind generator and the FES system can be transmitted stably to the microgrid without strong fluctuations, as shown in Figure 7.

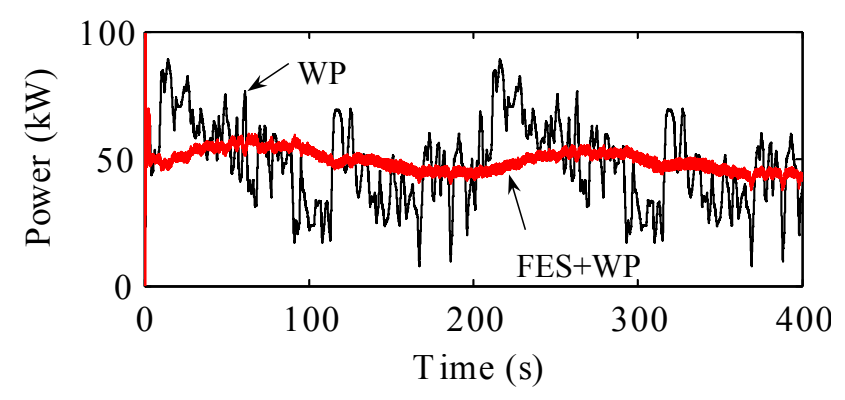

(a)

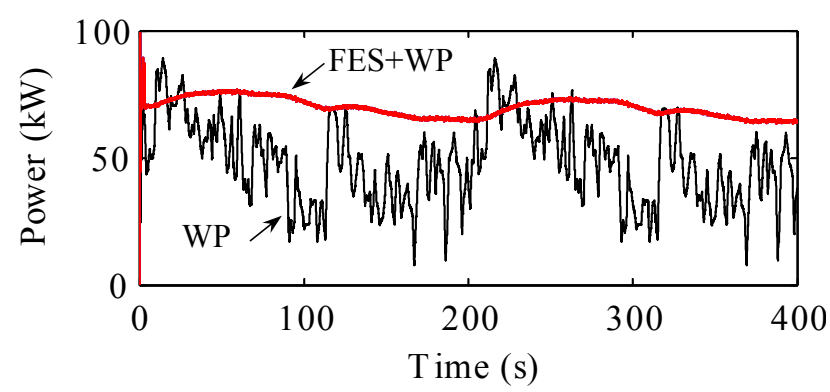

(b)

Figure 7. FES power and wind power: (a) the conventional FES system; (b) the proposed FES system.

For instance, at approximately $20 \mathrm{~s}$, the wind speed increases to a level above the mean speed, resulting in an increase in the wind power. At this point, the FES system is in the charging mode, in order to absorb the generated wind power. At approximately $100 \mathrm{~s}$, the wind power decreases owing to a drop in the wind speed. Thus, the FES system is in the discharging mode to compensate for the drop in the wind power. As a result, because of the charging and discharging of the FES system, as shown in Figure 8, the fluctuations in the wind power can be reduced. The speed of the FES system, shown in Figure 9, depends on its charging and discharging modes. It can be seen that the speed of the FES system is always in the allowable range.

Finally, both the conventional FES system and the proposed FES system exhibited good performance with respect to the smoothing of wind power. However, for the proposed FES system, the total wind power and the FES power are higher than those of the conventional FES system, because of the constant output power of the GSC. 


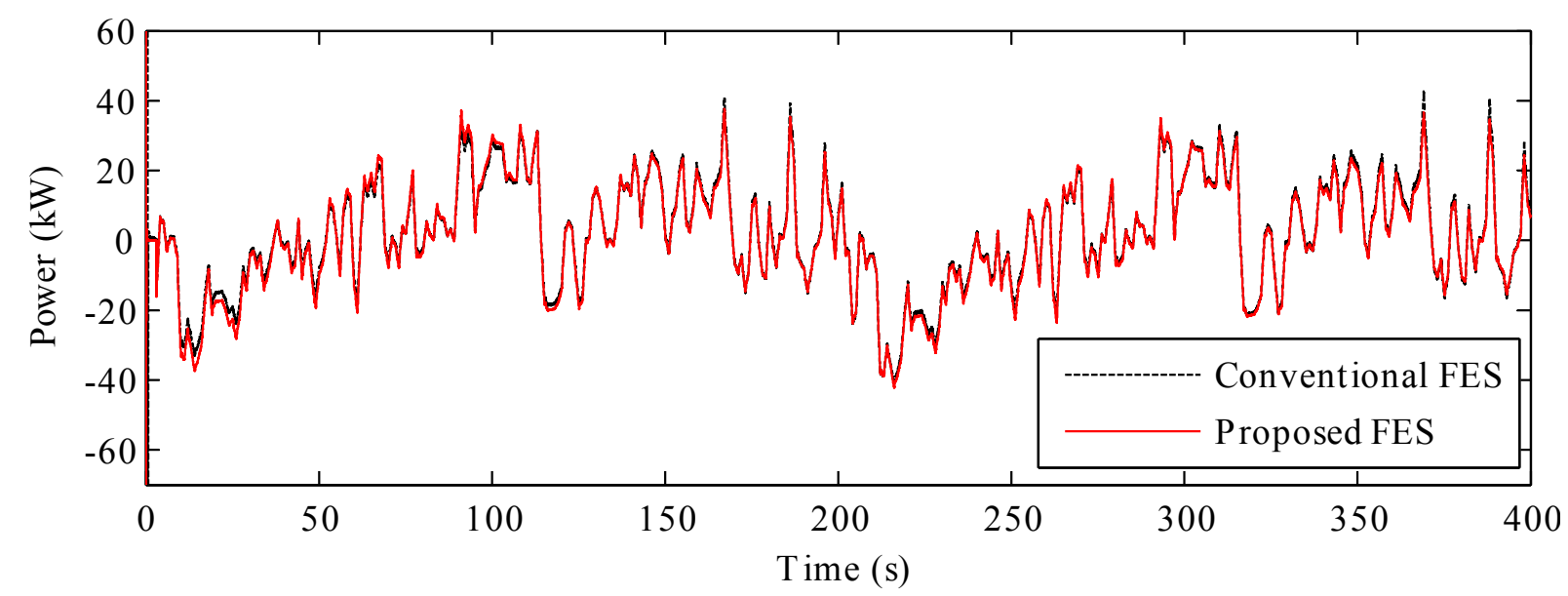

Figure 8. Stator powers of the FES systems.

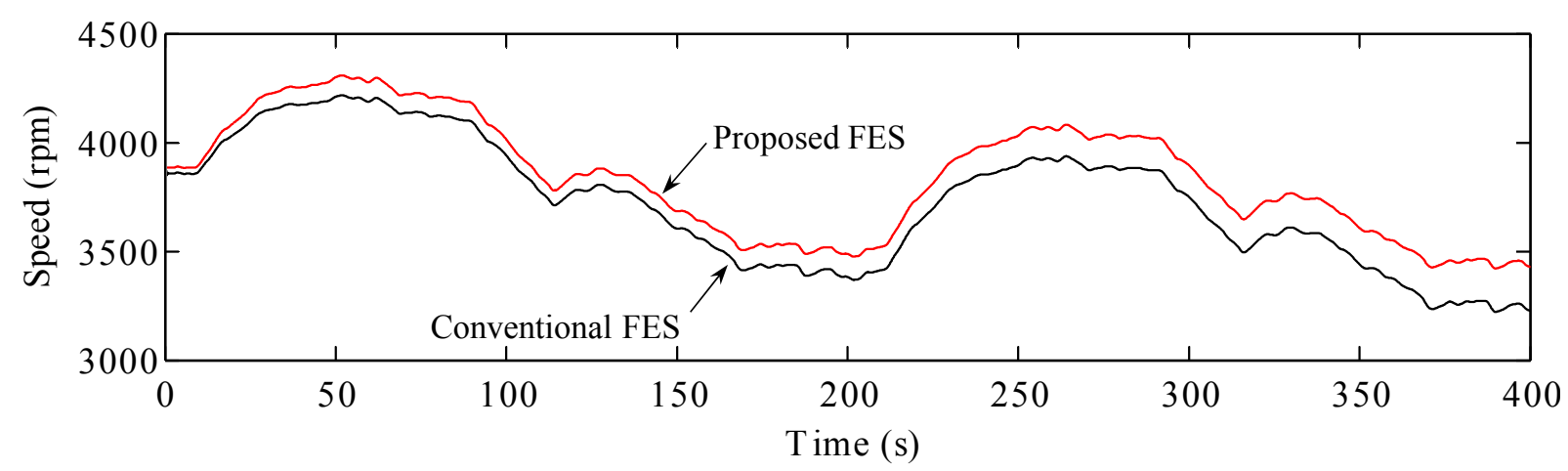

Figure 9. Speeds of the FES systems.

\subsection{Frequency Control and Voltage Control Modes}

A three-phase-to-ground fault is applied at $200 \mathrm{~s}$ on the high-voltage side of a transformer connected to the utility grid. The fault is cleared after five cycles by opening the circuit breaker placed at the PCC. Thus, the microgrid is operated in the islanded mode. Figure 10 shows the frequency and Figure 11 shows the AC voltage of the microgrid. The frequency is controlled by the MSC in the case of the conventional FES system and the GSC in the case of the proposed FES system. The voltage is controlled by the MSC in both the conventional FES system and the proposed one. It can be seen that both systems can stably control the frequency as well as the AC voltage of the microgrid.

However, in case of the conventional FES system, at approximately $370 \mathrm{~s}$, dramatic changes occur in the frequency and voltage, owing to a sudden fall in the wind speed. These changes can be explained on the basis of the action of the FES system. The sudden drop in the wind speed leads to a marked increase in the FES power, in order to compensate for the drop in the wind power, as shown in Figure 12. This action of the FES system causes a sudden change in the DC-link voltage of the back-to-back converter (Figure 13a). The MSC controlled the FES power is affected directly by this sudden change in the DC-link voltage. As a result, the imbalance between the power supply and the power demand causes a dramatic change in the frequency and voltage of the microgrid. 


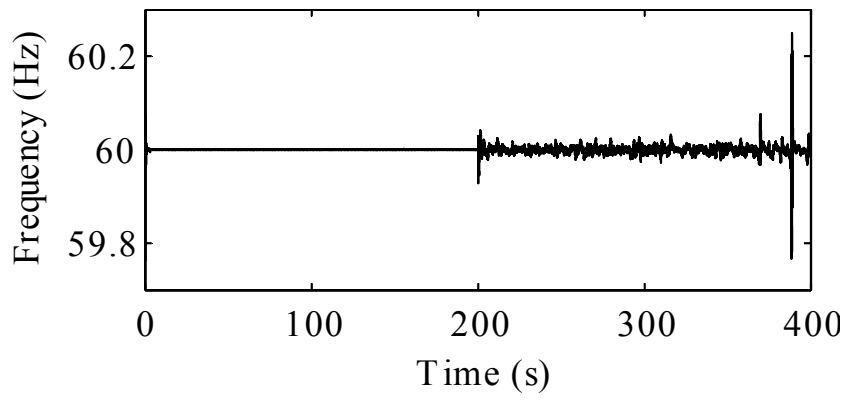

(a)

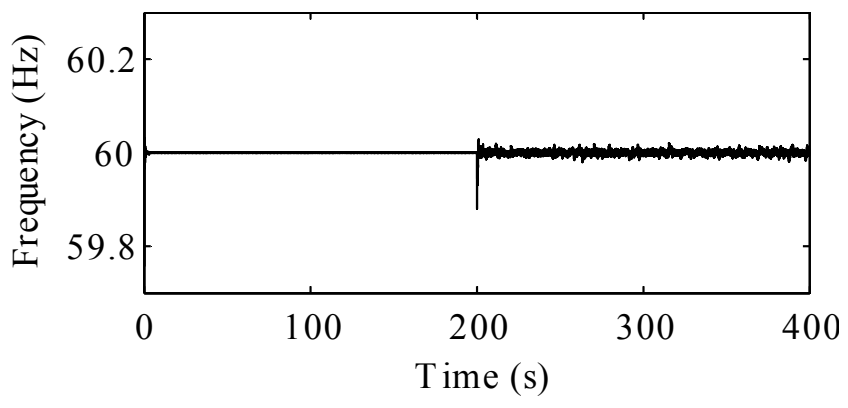

(b)

Figure 10. Frequencies of the microgrid system: (a) microgrid with the conventional FES system; (b) microgrid with the proposed FES system.

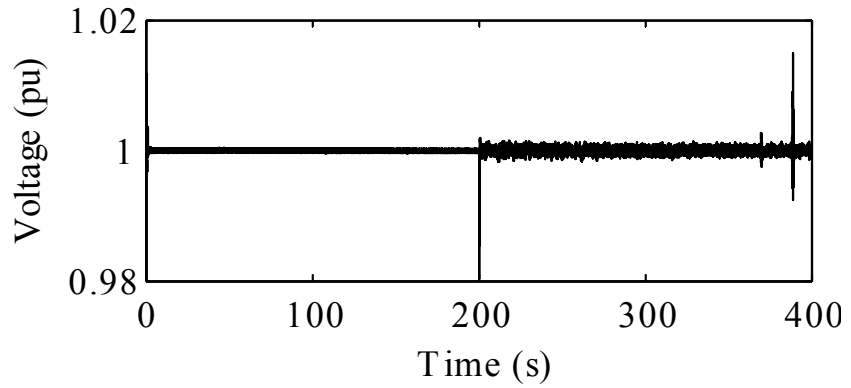

(a)

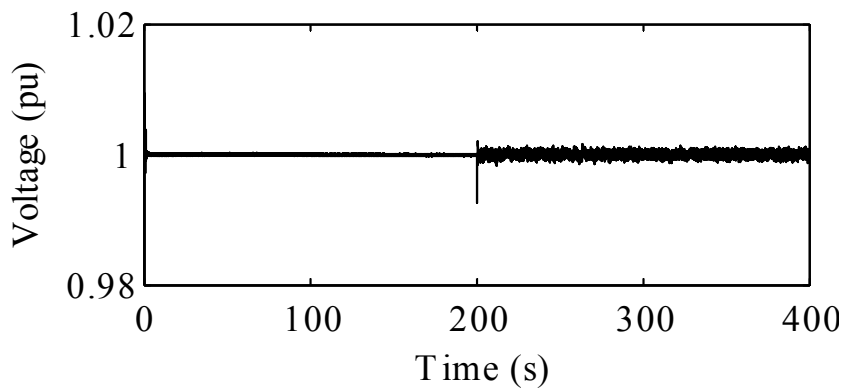

(b)

Figure 11. Voltages of the microgrid system: (a) microgrid with the conventional FES system; (b) microgrid with the proposed FES system.

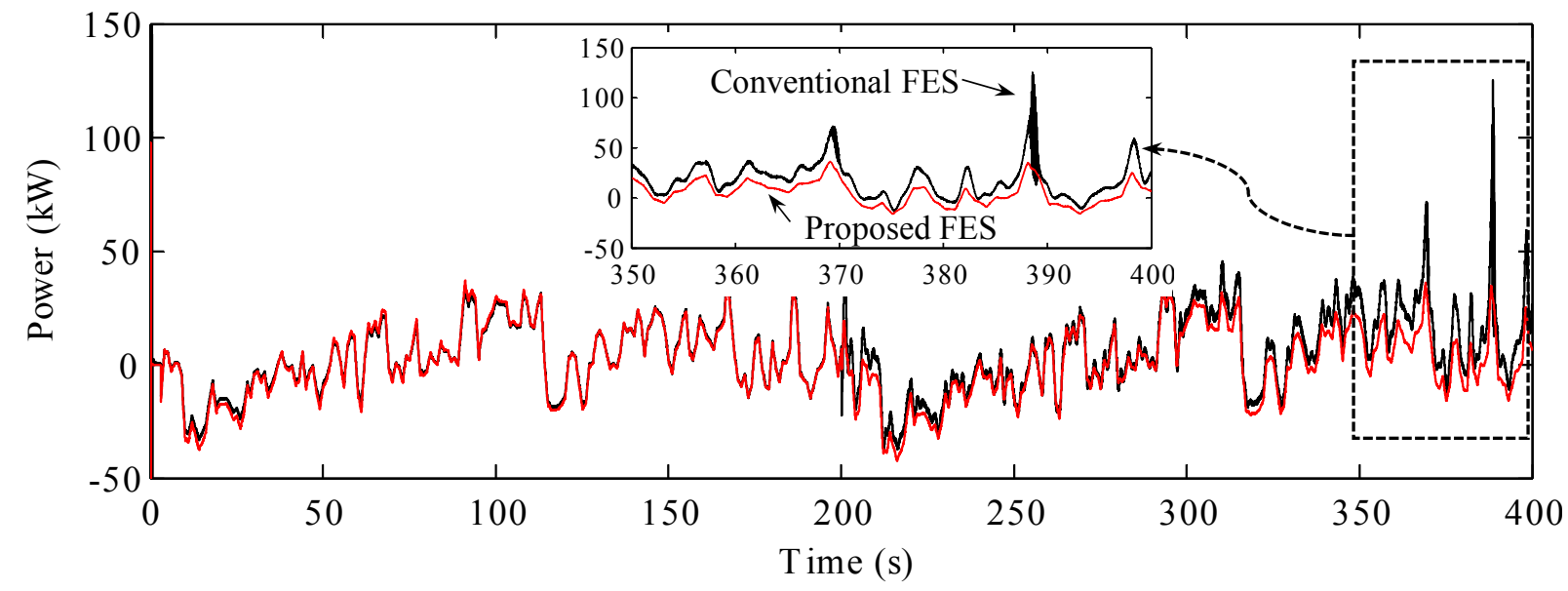

Figure 12. Stator powers of the FES systems.

In comparison, in the case of the proposed FES system, the DC-link voltage is controlled independently by the battery-side converter, as shown in Figure 13b. Thus, the DC-link voltage is not affected significantly by the dramatic change in the FES power. The MSC control system coordinates with the GSC control system, allowing for stable control of the frequency and voltage of the microgrid. Although the ripple in the DC-link voltage of the proposed FES system is higher than for the conventional FES system, owing to the DC-DC converter in the proposed FES system, the DC-link voltage of the proposed FES system is still in the desirable range. 


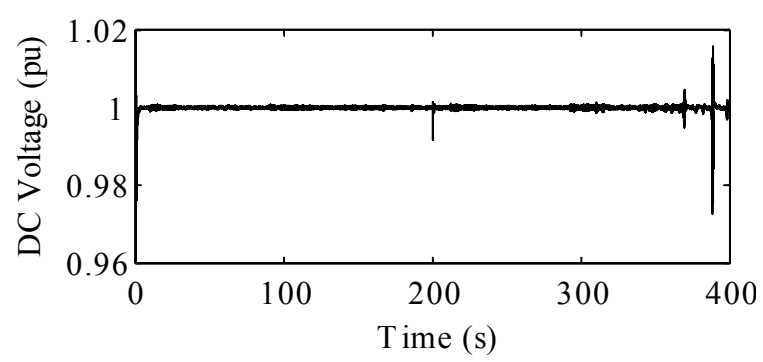

(a)

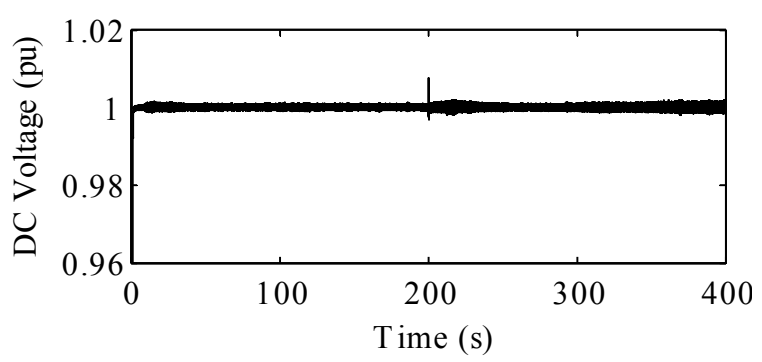

(b)

Figure 13. DC-link voltages of the back-to-back converter: (a) the conventional FES system; (b) the proposed FES system.

Figure 14 shows the stator and GSC powers of the proposed FES system. As mentioned in Section 3.3, the MSC controls the stator power to compensate for the wind power during both the grid-connected mode and the islanded mode. The fluctuations in the stator power represent the charging and discharging of the FES system.

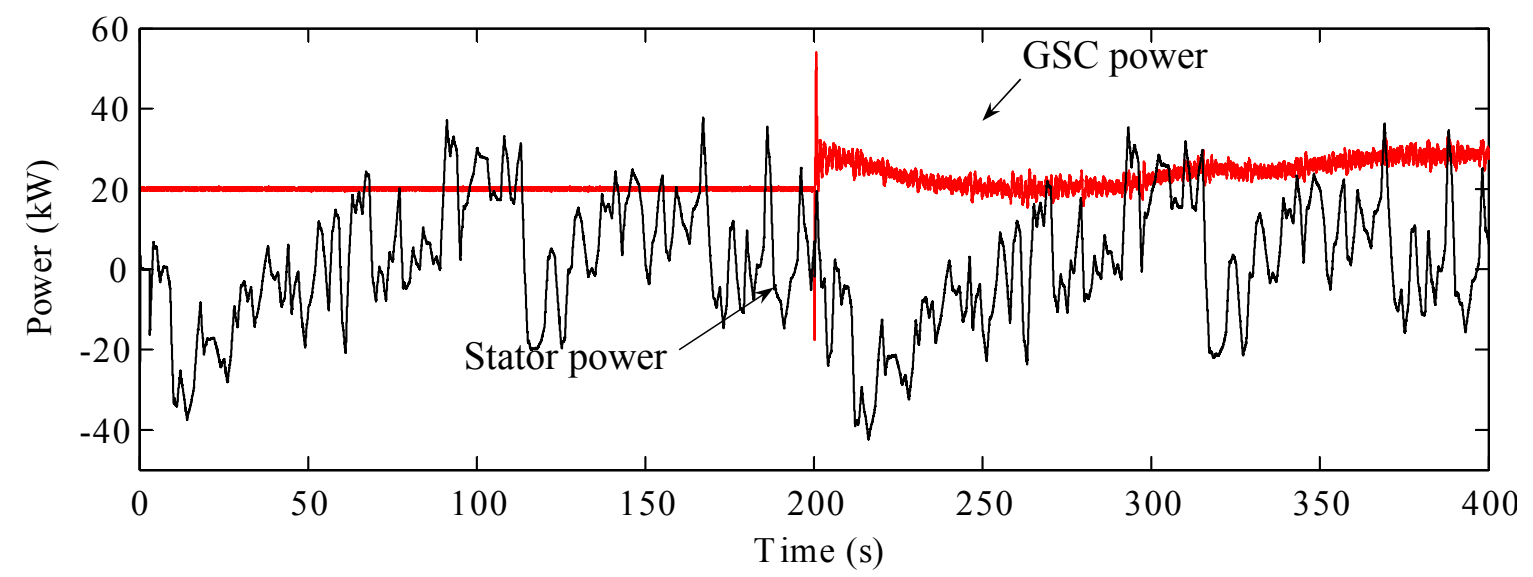

Figure 14. Stator power and GSC power of the proposed FES system.

The FES system is a short-term energy storage system that can be frequently charged and discharged. In comparison, the GSC controls the GSC power stored in the battery during the grid-connected mode as well as the frequency during the islanded mode. The frequency of the microgrid represents the relationship between the power supply and the power demand. Strong fluctuations in the frequency represent significant differences in the suppliable power and the power demand. The GSC control system coordinates with the MSC control system in the frequency-control mode. After the smoothing of the wind power, the imbalance between the power supply and the power demand is compensated for by the GSC power. Thus, the frequency of the microgrid can be controlled in a stable manner. The variations in the GSC power reflect the charging and discharging of modes the battery. As shown in Figure 13, a positive GSC power is indicative of the discharging mode of the battery. The battery cannot charge and discharge frequently, owing to its chemical characteristics.

\subsection{Rating of the FES System}

In Sections 5.1 and 5.2, we described the performance of an FES system that had an energy of 3.2 MJ. In this section, we consider an FES system that has an energy of $2 \mathrm{MJ}\left(J=23.5 \mathrm{kgm}^{2}\right)$. 
The results shown in Figure 15 indicate clearly that the proposed FES system exhibited good performance in the islanded mode. In spite of the lower energy rating of this FES system, it could control the frequency of the microgrid in a stable manner. However, in case of the conventional FES system, the frequency could be controlled stably only until the wind speed dropped to the lowest level. A loss of control of the FES system causes a fall in the frequency.

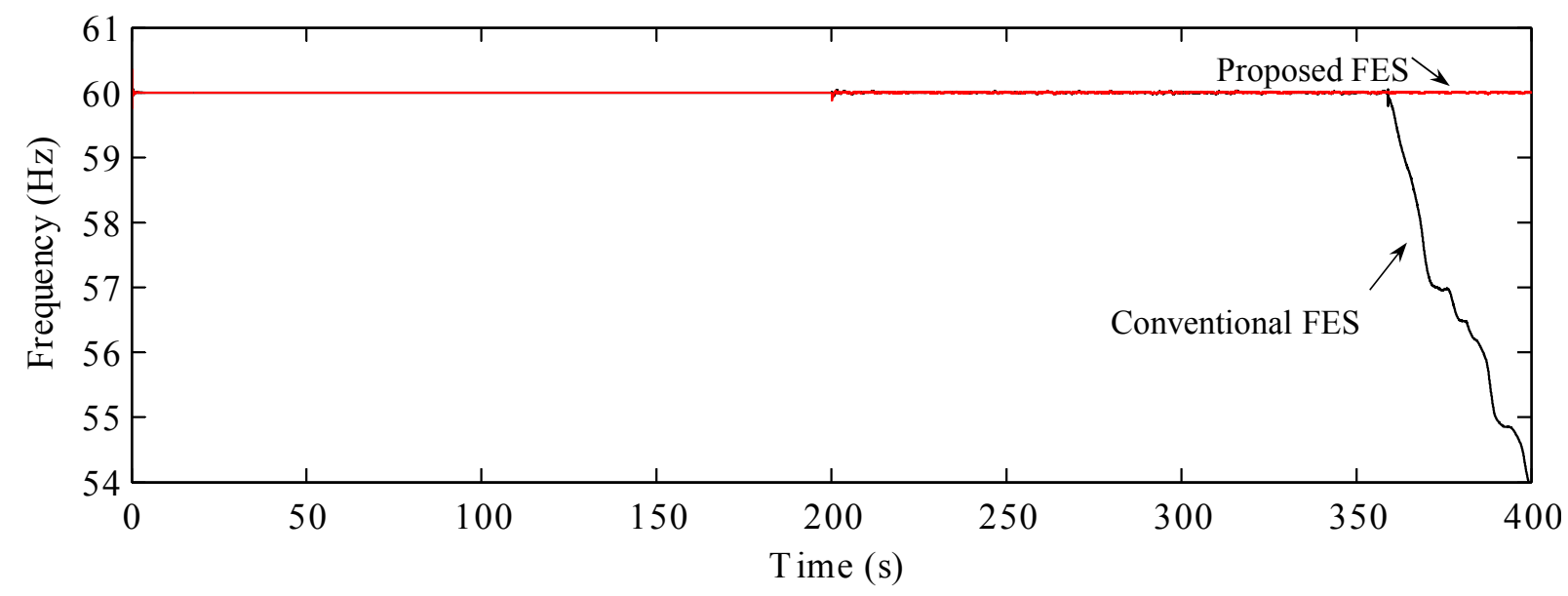

Figure 15. Frequency of the microgrid.

As shown in Figure 16, the speed of the conventional FES system reduces to the lowest level, leading to the system becoming uncontrollable. The conventional FES system could not control the output power to compensate for the drop in the wind power. Consequently, the power imbalance caused by the loss of one of the power supplies led to the collapse of the microgrid operations.

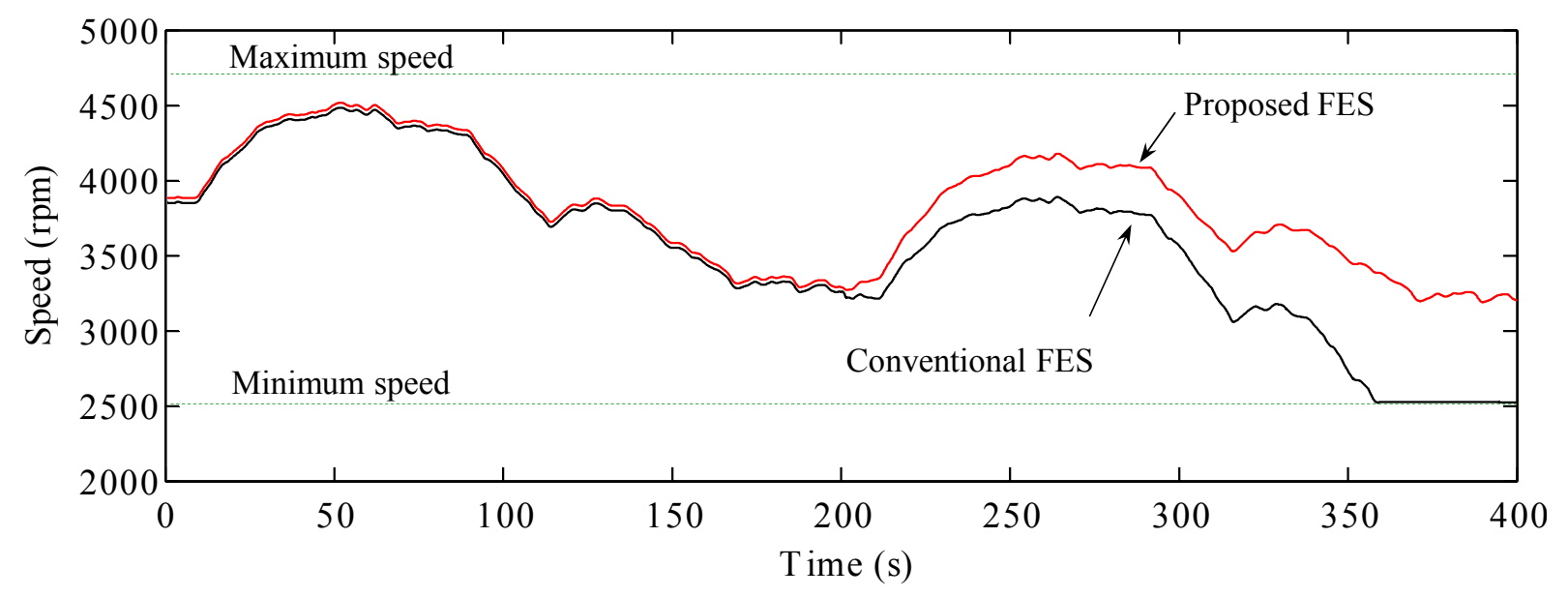

Figure 16. Speed of the FES systems.

\section{Conclusions}

In this paper, we compared the performances of a conventional FES system and a newly proposed one, which had a battery, when used with a microgrid. The addition of an FES system in the microgrid can improve the power quality features, including the frequency and voltage. The fluctuations in the wind power, which have an effect on the frequency of the microgrid, can be reduced by charging or discharging the FES system, as required. In order to control the frequency of the microgrid in a stable 
manner, very large FES systems are usually required. However, in this paper, we demonstrated that the microgrid power frequency can be controlled stably by using a small FES system such as the one proposed. The coordination of the MSC and GSC control systems in the proposed FES system allows for the rating of the FES system to be lowered. The results of simulations showed that the proposed FES system exhibited better performance than did the conventional FES system.

In the proposed FES system, we assumed an ideal battery whose state of charge was not known. However, it is necessary to take into account the characteristics of the battery in the simulations. Moreover, the control system of the proposed FES system can be integrated into hardware-in-the loop simulations.

\section{Acknowledgments}

This work was supported by an Incheon National University Research Grant awarded in 2012.

\section{Author Contributions}

The paper was a collaborative effort between the authors. The authors contributed collectively to the theoretical analysis, modeling, simulation, and manuscript preparation.

\section{Conflicts of Interest}

The authors declare no conflict of interest.

\section{References}

1. Hatziargyriou, N.; Asano, H.; Iravani, R.; Marnay, C. Microgrids. IEEE Power Energy 2008, 6, 26-29.

2. Keyhani, A. Design of Smart Power Grid Renewable Energy Systems, 1st ed.; Wiley-IEEE Press: Hoboken, NJ, USA, 2011; pp. 336-392.

3. Kim, H.-M.; Lim, Y.; Kinoshita, T. An Intelligent Multiagent System for Autonomous Microgrid Operation. Energies 2012, 5, 3347-3362.

4. Kim, H.-M.; Kinoshita, T.; Shin, M.-C. A Multiagent System for Autonomous Operation of Islanded Microgrids Based on a Power Market Environment. Energies 2010, 3, 1972-1990.

5. Kim, H.-M.; Kinoshita, T. A Multiagent System for Microgrid Operation in the Grid-Interconnected Mode. J. Electr. Eng. Technol. 2010, 2, 246-254.

6. Adhikari, S.; Li, F. Coordinated V-f and P-Q Control of Solar Photovoltaic Generators with MPPT and Battery Storage in Microgrids. IEEE Trans. Smart Grid 2014, 5, 1270-1281.

7. Serban, I.; Marinescu, C. Control Strategy of Three-Phase Battery Energy Storage Systems for Frequency Support in Microgrids and with Uninterrupted Supply of Local Loads. IEEE Trans. Power Electron. 2014, 29, 5010-5020.

8. Molina, M.G.; Mercado, P.E. Power Flow Stabilization and Control of Microgrid with Wind Generation by Superconducting Magnetic Energy Storage. IEEE Trans. Power Electron. 2011, 26, 910-922. 
9. Ngamroo, I.; Karaipoom, T. Improving Low-Voltage Ride-Through Performance and Alleviating Power Fluctuation of DFIG Wind Turbine in DC Microgrid by Optimal SMES With Fault Current Limiting Function. IEEE Trans. Appl. Supercond. 2014, 24, doi:10.1109/TASC.2014.2333031.

10. Gu, W.; Liu, W.; Wu, Z.; Zhao, B.; Chen, W. Cooperative Control to Enhance the Frequency Stability of Islanded Microgrids with DFIG-SMES. Energies 2013, 6, 3951-3971.

11. Inthamoussou, F.A.; Pegueroles-Queralt, J.; Bianchi, F.D. Control of a Supercapacitor Energy Storage System for Microgrid Applications. IEEE Trans. Energy Convers. 2013, 28, 690-697.

12. Ghazanfari, A.; Hamzeh, M.; Mokhtari, H.; Karimi, H. Active Power Management of Multihybrid Fuel Cell/Supercapacitor Power Conversion System in a Medium Voltage Microgrid. IEEE Trans. Smart Grid 2012, 3, 1903-1910.

13. Islam, F.; Al-Durra, A.; Muyeen, S.M. Smoothing of Wind Farm Output by Prediction and Supervisory-Control-Unit-Based FESS. IEEE Trans. Sustain. Energy 2013, 4, 925-933.

14. Suvire, G.O.; Molina, M.G.; Mercado, P.E. Improving the Integration of Wind Power Generation into AC Microgrids Using Flywheel Energy Storage. IEEE Trans. Smart Grid 2012, 3, 1945-1954.

15. Sebastián, R.; Peña Alzola, R. Flywheel Energy Storage Systems: Review and Simulation for an Isolated Wind Power System. Renew. Sustain. Energy Rev. 2012, 16, 6803-6813.

16. Hussain, E.K.; Benchebra, D.; Atallah, K.; Ooi, H.S.; Burke, M.; Goodwin, A. A Flywheel Energy Storage System for an Isolated Micro-Grid. In Proceedings of the Renewable Power Generation Conference, Naples, Italy, 24-25 September 2014; pp. 1-6.

17. Cimuca, G.; Breban, S.; Radulescu, M.M.; Saudemont, C.; Robyns, B. Design and Control Strategies of an Induction-Machine-Based Flywheel Energy Storage System Associated to a Variable-Speed Wind Generator. IEEE Trans. Energy Convers. 2010, 25, 526-534.

18. Jerbi, L.; Krichen, L.; Ouali, A. A Fuzzy Logic Supervisor for Active and Reactive Power Control of a Variable Speed Wind Energy Conversion System Associated to a Flywheel Storage System. Electr. Power Syst. Res. 2009, 79, 919-925.

19. Cimuca, G.O.; Saudemont, C.; Robyns, B.; Radulescu, M.M. Control and Performance Evaluation of a Flywheel Energy-Storage System Associated to a Variable-Speed Wind Generator. IEEE Trans. Ind. Electron. 2006, 53, 1074-1085.

20. Cardenas, R.; Pena, R.; Asher, G.M.; Clare, J.; Blasco-Gimenez, R. Control Strategies for Power Smoothing Using a Flywheel Driven by a Sensorless Vector-Controlled Induction Machine Operating in a Wide Speed Range. IEEE Trans. Ind. Electron. 2004, 51, 603-614.

21. Chang, X.; Li, Y.; Zhang, W.; Wang, N.; Xue, W. Active Disturbance Rejection Control for a Flywheel Energy Storage System. IEEE Trans. Ind. Electron. 2015, 62, 991-1001.

22. Suvire, G.O.; Mercado, P.E. DSTATCOM with Flywheel Energy Storage System for Wind Energy Applications: Control Design and Simulation. Electr. Power Syst. Res. 2010, 80, 345-353.

23. Cardenas, R.; Peña, R.; Perez, M.; Clare, J.; Asher, G.; Wheeler, P. Power Smoothing Using a Flywheel Driven by a Switched Reluctance Machine. IEEE Trans. Ind. Electron. 2006, 53, 1086-1093.

24. Wang, L.; Yu, J.-Y.; Chen, Y.-T. Dynamic Stability Improvement of an Integrated Offshore Wind and Marine-Current Farm Using a Flywheel Energy-Storage System. Renew. Power Génér. 2011, $5,387-396$. 
25. Toshiba. World's First Successful Commercial Operation of Double-Fed Adjustable-Speed Flywheel Generating System, 1997. Available online: https://www.toshiba.co.jp/tech/review/1997/ high97/power/p3/index.htm (accessed on 21 January 2015).

26. Genta, G. Application of Flywheel Energy Storage Systems. In Kinetic Energy Storage: Theory and Practice of Advanced Flywheel Systems; Butterworth: London, UK, 1985; pp. 27-46.

27. Yazdani, A.; Iravani, R. Voltage-Sourced Converters in Power Systems: Modeling, Control and Applications, 1st ed.; Wiley-IEEE Press: Hoboken, NJ, USA, 2010; pp. 204-245.

28. Krause, P.; Wasynczuk, O.; Sudhoff, S.; Pekarek, D. Analysis of Electric Machinery and Drive Systems, 3rd ed.; Wiley-IEEE Press: Hoboken, NJ, USA, 2013; pp. 215-267.

29. Teodorescu, R.; Liserre, M.; Rodríguez, P. Grid Converters for Photovoltaic and Wind Power Systems, 1st ed.; Wiley-IEEE Press: West Sussex, UK, 2011; pp. 313-353.

30. Leuchter, J.; Bauer, P.; Bojda, P.; Rerucha, V. Bi-directional DC-DC Converters for Supercapacitor Based Energy Buffer for Electrical Gen-Sets. In Proceedings of Power Electronics and Applications Conference, Aalborg, Denmark, 2-5 September 2007; pp. 1-10.

31. Natesan, C.; Ajithan, S.; Mani, S.; Kandhasamy, P. Applicability of Droop Regulation Technique in Microgrid-A Survey. Eng. J. 2014, 18, 23-35.

32. Wu, B.; Lang, Y.; Zargari, N.; Kouro, S. Power Conversion and Control of Wind Energy Systems, 1st ed.; Wiley-IEEE Press: Hoboken, NJ, USA, 2011; pp. 153-170.

(C) 2015 by the authors; licensee MDPI, Basel, Switzerland. This article is an open access article distributed under the terms and conditions of the Creative Commons Attribution license (http://creativecommons.org/licenses/by/4.0/). 